\title{
BMJ Open Effect of fenofibrate on plasma apolipoprotein C-III levels: a systematic review and meta-analysis of randomised placebo-controlled trials
}

\author{
Amirhossein Sahebkar, ${ }^{1,2,3}$ Luis E Simental-Mendía, ${ }^{4}$ Niki Katsiki, ${ }^{5}$ Željko Reiner, ${ }^{6}$ \\ Maciej Banach, ${ }^{7,8}$ Matteo Pirro, ${ }^{9}$ Stephen L Atkin ${ }^{10}$
}

To cite: Sahebkar A, SimentalMendía LE, Katsiki N, et al. Effect of fenofibrate on plasma apolipoprotein C-III levels: a systematic review and metaanalysis of randomised placebocontrolled trials. BMJ Open 2018;8:e21508. doi:10.1136/ bmjopen-2018-021508

\section{- Prepublication history and} additional material for this paper are available online. To view these files, please visit the journal online (http://dx.doi. org/10.1136/bmjopen-2018021508).

Received 6 January 2018 Revised 26 June 2018 Accepted 24 October 2018

\section{Check for updates}

(C) Author(s) (or their employer(s)) 2018. Re-use permitted under CC BY-NC. No commercial re-use. See rights and permissions. Published by BMJ.

For numbered affiliations see end of article.

Correspondence to Dr Stephen L Atkin; sla2002@qatar-med.cornell.edu

\section{ABSTRACT}

Objectives This meta-analysis of randomised placebocontrolled clinical trials aimed to assess the effect of fenofibrate on apolipoprotein C-III (apo C-III), a key regulator of triglyceride metabolism.

Materials and methods Randomised placebo-controlled trials investigating the impact of fenofibrate treatment on apo C-III levels were searched in PubMed-Medline, Scopus, Web of Science and Google Scholar databases from inception to 18 August 2017. Quantitative data synthesis was determined by a random-effects model and generic inverse variance method. Sensitivity analysis was conducted using the leave-one-out method. A weighted random-effects meta-regression was performed to evaluate glycaemic parameter confounders.

Results Meta-analysis of 10 clinical trials involving 477 subjects showed fenofibrate therapy decreased apo C-III levels (weighted mean difference (WMD) $-4.78 \mathrm{mg} / \mathrm{dL}$, $95 \% \mathrm{Cl}-6.95$ to $\left.-2.61, \mathrm{p}<0.001 ; \mathrm{I}^{2} 66.87 \%\right)$. Subgroup analysis showed that fenofibrate reduced plasma apo C-III concentrations in subgroups of trials with treatment durations of either $<12$ weeks (WMD $-4.50 \mathrm{mg} / \mathrm{dL}$, $\mathrm{p}=0.001$ ) or $\geq 12$ weeks (WMD: $-4.73 \mathrm{mg} / \mathrm{dL}, \mathrm{p}=0.009$ ) and doses of fenofibrate $<200 \mathrm{mg} /$ day $(\mathrm{WMD}-6.33 \mathrm{mg} / \mathrm{dL}$, $p<0.001)$ and $>200 \mathrm{mg} / \mathrm{day}(\mathrm{p}=0.006)$, with no significant difference between the subgroups.

Conclusion This meta-analysis found that fenofibrate therapy significantly decreases apo C-III levels, an effect evident with both short-term treatment and doses less than $200 \mathrm{mg} /$ day.

\section{INTRODUCTION}

Elevated triglycerides have been shown to be an independent marker of coronary artery disease (CAD). ${ }^{1-3}$ Apolipoprotein C-III (apo C-III) is a key regulator of triglyceride metabolism that mediates its effects through lipoprotein lipase (LPL) inhibition. However, indirect LPL-independent mechanisms are also present, shown by inhibition of apo C-III messenger RNA and a reduction of apo C-III levels in patients with LPL deficiency. ${ }^{45}$ Apo C-III also inhibits hepatic lipase activity that decreases the conversion of very-low-density
Strengths and limitations of this study

- This was the first systematic review to determine the effect of fenofibrate on plasma apolipoprotein C-III (apo C-III).

- The strength of this study was the use of the meta-analysis that used the increased population size compared with individual studies that were small and, in some instances, underpowered to discern if fenofibrate had an effect on plasma apo C-III.

- The limitation was that the small number of trials, lack of studies in patients with hyperapolipoproteinaemia C-III and lack of presenting gender-stratified results by individual studies.

lipoprotein (VLDL) to intermediate-density lipoprotein (IDL) and low-density lipoprotein (LDL). ${ }^{6}$ Recently, apo C-III was shown to be significantly associated with incident $\mathrm{CAD}$ in the European Prospective Investigation of Cancer (EPIC)-Norfolk prospective population study. ${ }^{7}$ It has been suggested that apo C-III may exert atherogenic properties by both direct (via enhancing inflammation) and indirect (via promoting hypertriglyceridaemia) mechanisms. ${ }^{8}$

Fibrates are a therapeutic class of drugs that are used primarily for the treatment of hypertriglyceridaemia, but are also for combined dyslipidaemias in which both triglycerides and LDL-cholesterol (LDL-C) are elevated..$^{9-11}$ Fibrates also have several pleiotropic activities described recently. ${ }^{12-18}$ Fenofibrate is the most commonly used fibrate that induces lipoprotein lipolysis, fatty acid uptake and increase high-density lipoprotein (HDL) production, ${ }^{19}{ }^{20}$ while reducing plasma triglyceride levels by $20 \%-30 \% .^{21}$ Mechanistically, fenofibrate activates peroxisome proliferator activated receptor alpha through modulation of genes expression related to fatty acid and lipoprotein metabolism. ${ }^{22-24}$ 
This meta-analysis of randomised placebo-controlled clinical trials using fenofibrate therapy aimed to determine its effect on apo C-III levels.

\section{METHODS}

\section{Search strategy}

This study was designed according to the guidelines of the Preferred Reporting Items for Systematic Reviews and Meta-Analyses statement. ${ }^{25}$ PubMed-Medline, Scopus and ISI Web of Knowledge databases were searched using the following search terms in titles and abstracts: fenofibrate AND (apoCIII OR apoC-III OR 'apo CIII' OR 'apo C-III' OR apoC3 OR 'apo C3') AND (placebo OR placebo-controlled). The wild-card term ' $*$ ' was used to increase the sensitivity of the search strategy. An example of the search strategy employed in PubMed-Medline is shown in online supplementary file 1 . The search was limited to articles published in English language. The literature was searched from inception to 18 August 2017.

\section{Study selection}

Original studies were included if they met the following inclusion criteria: (1) being a randomised placebo-controlled clinical trial with either parallel or cross-over design, (2) investigating the impact of fenofibrate versus placebo on total circulating concentrations of apo C-III and (3) presentation of sufficient information on apo C-III concentrations at baseline and at study end in both intervention and placebo groups or providing the net change values. Exclusion criteria were: (1) non-clinical studies; (2) uncontrolled or non-placebo-controlled studies; (3) observational studies with case-control, cross-sectional or cohort design; (4) reporting postprandial plasma apo C-III levels and (5) lack of sufficient information on baseline or follow-up total circulating apo C-III levels.

\section{Data extraction}

Eligible studies were reviewed and the following data were abstracted: (1) first author's name; (2) year of publication; (3) country where the study was performed; (4) study design; (5) number of participants in the statin and control groups; (6) fenofibrate dose; (7) duration of treatment; (8) age, gender and body mass index (BMI) of study participants and (9) baseline and follow-up concentrations of plasma lipids, lipoproteins and apolipoproteins including apo C-III. When apo C-III data were incompletely reported, authors of the respective article were contacted to obtain missing information. Two authors (AS and LES) reviewed the papers, and disagreements were resolved through discussion and consultation with a third author (SLA).

\section{Quality assessment}

The quality of involved studies in this meta-analysis was evaluated using the Cochrane criteria. Risk of bias in the studies considered in this meta-analysis was evaluated according to the Cochrane instructions. ${ }^{26}$

\section{Quantitative data synthesis}

Meta-analysis was conducted using Comprehensive Meta-Analysis V.2 software (Biostat, New Jersey, USA). A random-effects model (using DerSimonian-Laird method) and the generic inverse variance weighting method were used to compensate for the heterogeneity of studies in terms of study design, treatment duration and the characteristics of populations being studied. SDs of $\left[\left(\mathrm{SD}_{\text {pre-treatment }}\right)^{2}+\left(\mathrm{SD}_{\text {post-treatment }}\right)^{2}-\left(2 \mathrm{R} \times \mathrm{SD}_{\text {pre-treatment }} \times\right.\right.$ $\left.\left.\mathrm{SD}_{\text {post-treatment }}\right)\right]$, assuming a correlation coefficient $(\mathrm{r})=0.5$. Where SE of the mean (SEM) was only reported, SD was estimated using the following formula: $\mathrm{SD}=\mathrm{SEM} \times$ sqrt $(\mathrm{n})$, where $\mathrm{n}$ is the number of subjects. Heterogeneity was assessed quantitatively using Cochrane $Q$ and $\mathrm{I}^{2}$ statistic. All apo C-III values were collated in $\mathrm{mg} / \mathrm{L}$. Effect sizes were expressed as weighted mean difference (WMD) and 95\% CI. In order to avoid the double-counting problem in trials comparing multiple treatment arms versus a single control group, the number of subjects in the control group were divided by the number of treatment arms. In order to evaluate the influence of each study on the overall effect size, a sensitivity analysis was conducted using the leave-one-out method (ie, removing one study each time and repeating the analysis). ${ }^{27} 28$

\section{Meta-regression}

As potential confounders of treatment response, the duration of treatment and baseline plasma apo C-III concentrations were entered into a random-effects meta-regression model to explore their association with the estimated effect size on plasma apo C-III levels.

\section{Publication bias}

Evaluation of funnel plot, Begg's rank correlation and Egger's weighted regression tests were performed to assess the presence of publication bias in the meta-analysis. When there was evidence of funnel plot asymmetry, potentially missing studies were imputed using the "trim and fill' method. ${ }^{29}$ In case of a significant result, the number of potentially missing studies required to make the $p$ value non-significant was estimated using the 'failsafe N' method as another marker of publication bias.

\section{Patient and public involvement}

No patients or public were involved in this study.

\section{RESULTS}

Overall, 61 articles were found following multidatabase search. After screening of titles and abstracts, 22 articles were assessed in full text. Of these five articles were excluded because of lack of reporting serum/plasma total apo C-III concentrations, four because of duplicate reporting of data from the same population, two because of reporting postprandial apo C-III levels and one because of incomplete data on apo C-III levels. Therefore, 10 articles were found to be eligible for inclusion in the meta-analysis (figure 1). 


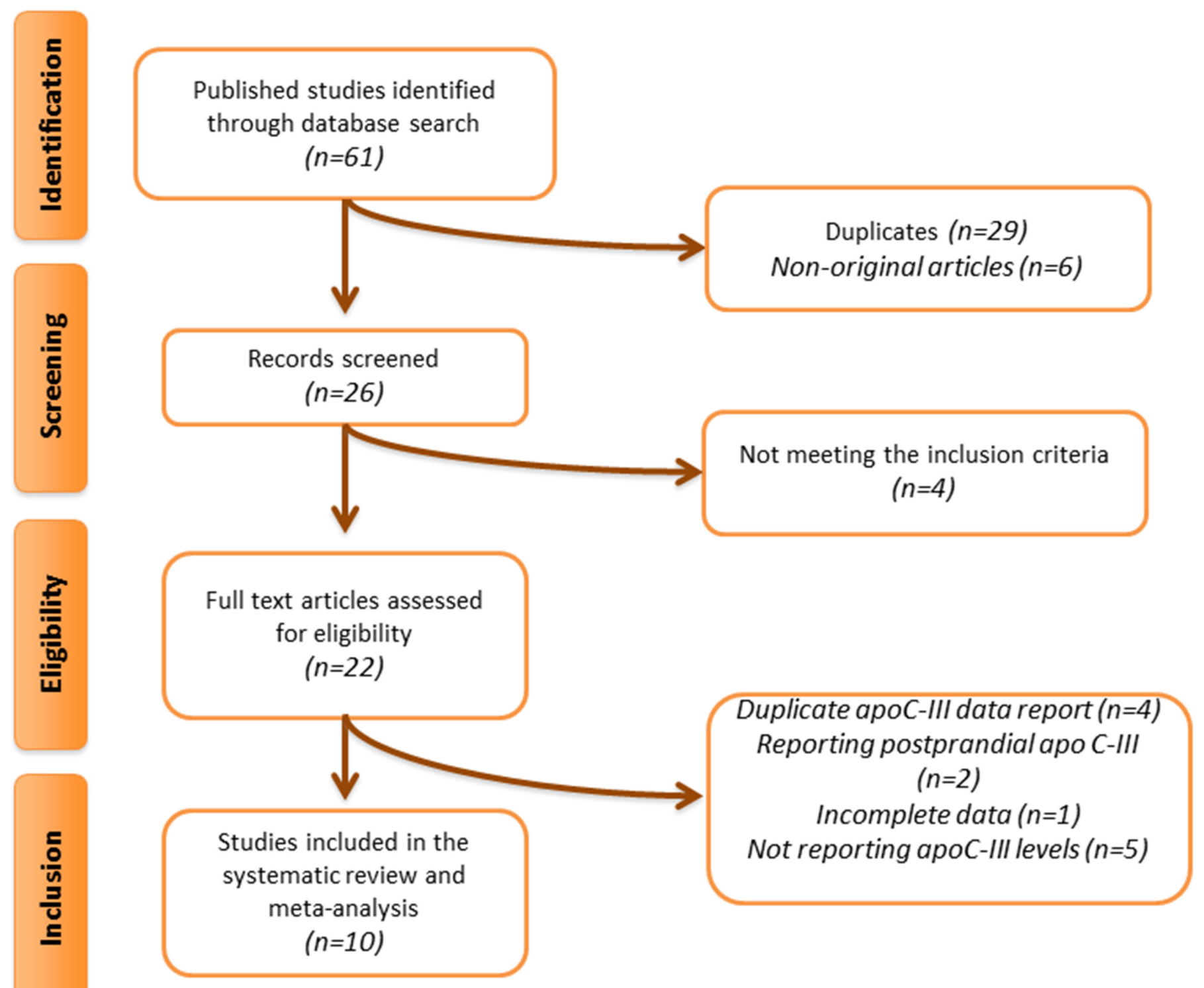

Figure 1 Flow chart of the number of studies identified and included into the meta-analysis. Apo C-III, apo C-III.

\section{Study characteristics}

Data were pooled from 10 randomised placebo-controlled clinical trials comprising a total of 477 subjects, including 265 and 212 participants in the fenofibrate and placebo arms respectively (individuals of the crossover trials were considered in the treatment and control groups). ${ }^{30-40}$ Clinical trials reported different doses of fenofibrate. The included studies were published between $2002^{34} 38$ and 2016. Treatment duration ranged from 2 weeks ${ }^{3640}$ to 12 weeks. ${ }^{30-34}$ Study designs of included trials were parallel $^{30} 343641$ and crossover. ${ }^{31} 333537-40$ Selected studies enrolled subjects with metabolic syndrome, ${ }^{30}$ type 2 diabetes, ${ }^{31}{ }^{33}$ hypertriglyceridaemia, ${ }^{32} 3538$ dyslipidaemia ${ }^{3436}$ and non-diabetic subjects. ${ }^{40}$ Characteristics of the included clinical trials are presented in table 1.

Risk of bias assessment

Most of the included studies showed insufficient information regarding the sequence generation and allocation concealment. Moreover, three trials had high risk of bias concerning blinding of participants, personnel and outcome assessors. ${ }^{36}{ }^{40}$ Nevertheless, all selected studies were characterised by a low risk of bias for incomplete outcome data and selective outcome reporting. Details of the risk of bias assessment are shown in table 2 .

\section{Quantitative data synthesis}

The present meta-analysis of data from 11 randomised placebo-controlled trials found a significant reduction of apo C-III plasma concentrations following treatment with fenofibrate (WMD: $-4.56 \mathrm{mg} / \mathrm{dL}, 95 \% \mathrm{CI}-6.53$ to -2.58 , $\mathrm{p}<0.001 ; \mathrm{I}^{2} 64.67 \%$ ) (figure 2). The effect size was robust in the leave-one-out sensitivity analysis (figure 2) and not mainly driven by any single study. Subgroup analysis showed significant decreases in plasma apo C-III levels caused by fenofibrate in subgroups of trials with treatment durations of either $<12$ weeks (WMD $-4.48 \mathrm{mg} / \mathrm{dL}$, $95 \% \mathrm{CI}-7.32$ to $-1.64, \mathrm{p}=0.002 ; \mathrm{I}^{2} 70.74 \%$ ) or $\geq 12$ weeks 


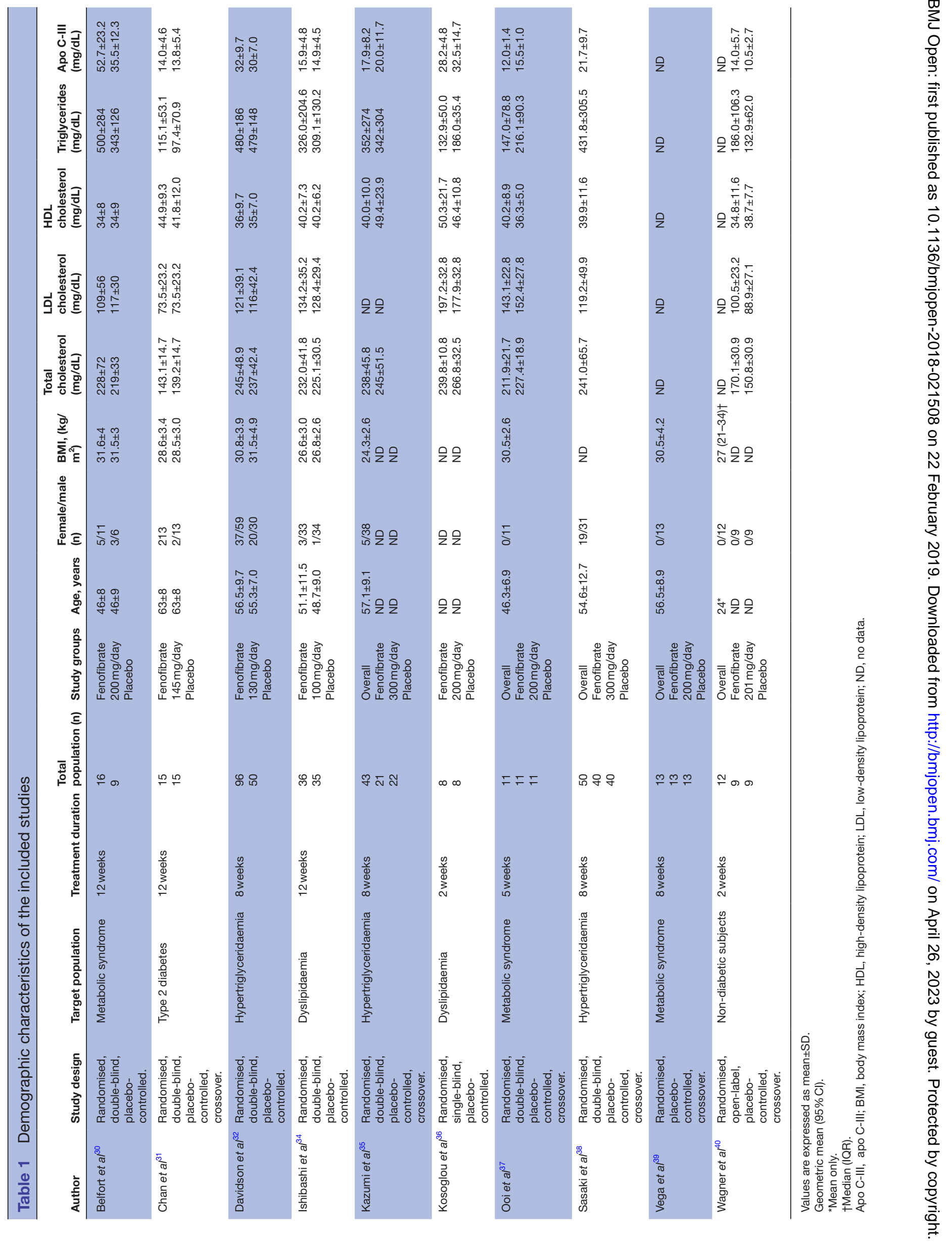


Table 2 Quality of bias assessment of the included studies according to the Cochrane guidelines

\begin{tabular}{|c|c|c|c|c|c|c|}
\hline Study & $\begin{array}{l}\text { Sequence } \\
\text { generation }\end{array}$ & $\begin{array}{l}\text { Allocation } \\
\text { concealment }\end{array}$ & $\begin{array}{l}\text { Blinding of } \\
\text { participants, } \\
\text { personnel and } \\
\text { outcome assessors }\end{array}$ & $\begin{array}{l}\text { Incomplete } \\
\text { outcome data }\end{array}$ & $\begin{array}{l}\text { Selective } \\
\text { outcome } \\
\text { reporting }\end{array}$ & $\begin{array}{l}\text { Other sources } \\
\text { of bias }\end{array}$ \\
\hline Belfort et $\left.a\right|^{30}$ & L & $U$ & U & L & L & U \\
\hline Chan et $\left.a\right|^{31}$ & U & $U$ & $U$ & L & $\mathrm{L}$ & U \\
\hline Davidson et $a l^{32}$ & U & $u$ & U & L & L & U \\
\hline Ishibashi et a/ $\left.\right|^{34}$ & L & $U$ & U & L & L & $U$ \\
\hline Kazumi et $a /^{35}$ & U & U & U & L & L & U \\
\hline Kosoglou et a $\beta^{36}$ & U & $U$ & $\mathrm{H}$ & L & L & U \\
\hline Ooi et $\left.a\right|^{37}$ & U & U & U & L & L & U \\
\hline Sasaki et $\left.a\right|^{38}$ & $U$ & L & U & L & L & $U$ \\
\hline Vega et $a l^{39}$ & $U$ & U & $\mathrm{H}$ & L & L & U \\
\hline Wagner et al ${ }^{40}$ & $U$ & U & $\mathrm{H}$ & L & L & $U$ \\
\hline
\end{tabular}

$\mathrm{H}$, high risk of bias; L, low risk of bias; $\mathrm{U}$, unclear risk of bias.

(WMD $-5.66 \mathrm{mg} / \mathrm{dL}, 95 \% \mathrm{CI}-10.15$ to $-1.16, \mathrm{p}=0.014 ; \mathrm{I}^{2}$ $69.61 \%)$, with no significant difference between the two subgroups $(p=0.664)$. With respect to fenofibrate dose, significant reductions were observed in both subgroups of trials with administered doses of $<200 \mathrm{mg} /$ day (WMD $-6.33 \mathrm{mg} / \mathrm{dL}, \quad 95 \% \mathrm{CI}-10.38$ to $-2.27, \mathrm{p}=0.002 ; \mathrm{I}^{2}$ $83.26 \%$ ) and $\geq 200 \mathrm{mg} /$ day (WMD $-3.47 \mathrm{mg} / \mathrm{dL}, 95 \%$ CI -5.51 to $-1.42, \mathrm{p}=0.001 ; \mathrm{I}^{2} 27.51 \%$ ). Again, there was no
Study name

\begin{tabular}{lrr}
\hline Belfort 2010 & $\begin{array}{r}\text { Difference } \\
\text { in means }\end{array}$ & $\begin{array}{c}\text { Standard } \\
\text { error }\end{array}$ \\
Chan 2010 & -21.200 & 7.397 \\
Davidson 2006 & -2.800 & 1.756 \\
Ishibashi 2016 & -10.580 & 1.564 \\
Kazumi 2003 & -5.520 & 1.123 \\
Kosoglou 2004 & -1.900 & 2.866 \\
Sasaki 2002 & -4.960 & 5.467 \\
Wagner 2005 & -5.600 & 2.206 \\
Ooi 2012 & -1.440 & 2.114 \\
Vega 2003 & -3.500 & 1.762 \\
& -2.700 & 1.290 \\
& -4.781 & 1.107
\end{tabular}

Statistics for each study

\begin{tabular}{|c|c|c|c|c|}
\hline Variance & $\begin{array}{c}\text { Lower } \\
\text { limit }\end{array}$ & $\begin{array}{c}\text { Upper } \\
\text { limit }\end{array}$ & Z-Value & p-Value \\
\hline 54.708 & -35.697 & -6.703 & -2.866 & 0.004 \\
\hline 3.083 & -6.241 & 0.641 & -1.595 & 0.111 \\
\hline 2.445 & -13.644 & -7.516 & -6.767 & 0.000 \\
\hline 1.260 & -7.720 & -3.320 & -4.917 & 0.000 \\
\hline 8.216 & -7.518 & 3.718 & -0.663 & 0.507 \\
\hline 29.891 & -15.676 & 5.756 & -0.907 & 0.364 \\
\hline 4.866 & -9.923 & -1.277 & -2.539 & 0.011 \\
\hline 4.469 & -5.583 & 2.703 & -0.681 & 0.496 \\
\hline 3.103 & -6.952 & -0.048 & -1.987 & 0.047 \\
\hline 1.665 & -5.229 & -0.171 & -2.092 & 0.036 \\
\hline 1.226 & -6.952 & -2.611 & -4.318 & 0.000 \\
\hline
\end{tabular}

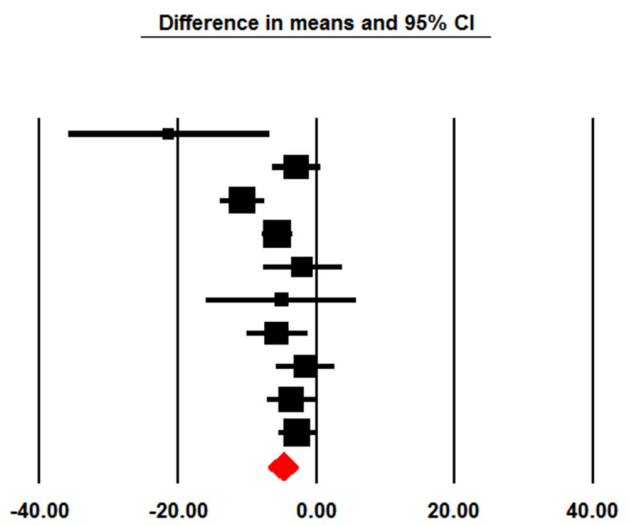

Favours Fenofibrate Favours Placebo

\begin{tabular}{|c|c|c|c|c|c|c|c|}
\hline \multirow[t]{2}{*}{ Study name } & \multirow[b]{2}{*}{ Point } & \multirow[b]{2}{*}{$\begin{array}{l}\text { Standard } \\
\text { error }\end{array}$} & \multicolumn{3}{|c|}{ Statistics with study removed } & \multirow[b]{2}{*}{ Z-Value } & \multirow[b]{2}{*}{ p-Value } \\
\hline & & & Variance & $\begin{array}{l}\text { Lower } \\
\text { limit }\end{array}$ & $\begin{array}{c}\text { Upper } \\
\text { limit }\end{array}$ & & \\
\hline Belfort 2010 & -4.470 & 1.034 & 1.069 & -6.497 & -2.444 & -4.324 & 0.000 \\
\hline Chan 2010 & -5.067 & 1.230 & 1.512 & -7.477 & -2.657 & -4.120 & 0.000 \\
\hline Davidson 2006 & -3.819 & 0.798 & 0.637 & -5.383 & -2.255 & -4.786 & 0.000 \\
\hline Ishibashi 2016 & -4.711 & 1.341 & 1.799 & -7.339 & -2.082 & -3.512 & 0.000 \\
\hline Kazumi 2003 & -5.041 & 1.176 & 1.382 & -7.345 & -2.737 & -4.288 & 0.000 \\
\hline Kosoglou 2004 & -4.782 & 1.153 & 1.330 & -7.043 & -2.522 & -4.146 & 0.000 \\
\hline Sasaki 2002 & -4.703 & 1.226 & 1.504 & -7.107 & -2.300 & -3.835 & 0.000 \\
\hline Wagner 2005 & -5.179 & 1.172 & 1.373 & -7.475 & -2.882 & -4.419 & 0.000 \\
\hline Ooi 2012 & -4.977 & 1.249 & 1.560 & -7.425 & -2.529 & -3.984 & 0.000 \\
\hline \multirow[t]{2}{*}{ Vega 2003} & -5.130 & 1.242 & 1.543 & -7.564 & -2.695 & -4.130 & 0.000 \\
\hline & -4.781 & 1.107 & 1.226 & -6.952 & -2.611 & -4.318 & 0.000 \\
\hline
\end{tabular}

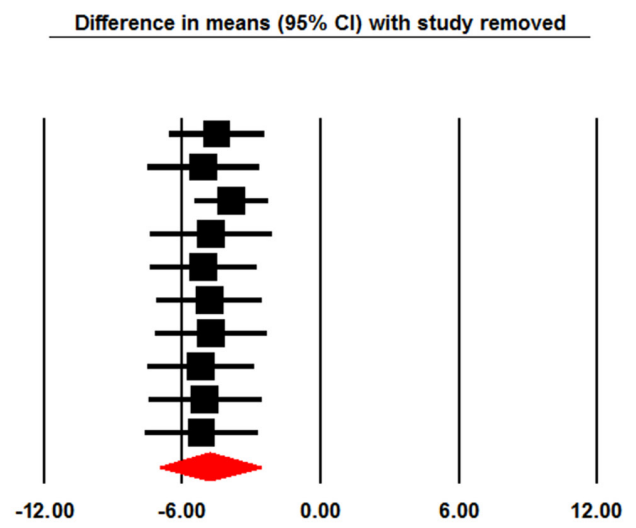

Favours Fenofibrate Favours Placebo

Figure 2 Forest plot displaying weighted mean difference and 95\% Cls for the effects of fenofibrate on circulating apolipoprotein C-III concentrations. The lower plot shows the results of leave-one-out sensitivity analysis. Analyses were performed using a random-effects model. 
Group by

Dose category

$<200 \mathrm{mg} /$ day

$<200 \mathrm{mg} /$ day

$<200 \mathrm{mg} /$ day

$<200 \mathrm{mg} /$ day

$>=200 \mathrm{mg} /$ day

$>=200 \mathrm{mg} /$ day

$>=200 \mathrm{mg} /$ day

$>=200 \mathrm{mg} /$ day

$>=200 \mathrm{mg} /$ day

$>=200 \mathrm{mg} / \mathrm{day}$

$>=200 \mathrm{mg} /$ day

$>=200 \mathrm{mg} /$ day

Overall
Study name

\begin{tabular}{lr}
\hline Chan 2010 & $\begin{array}{r}\text { Difference } \\
\text { in means }\end{array}$ \\
Davidson 2006 & -2.800 \\
Ishibashi 2016 & -10.580 \\
& -5.520 \\
Belfort 2010 & -6.328 \\
Kazumi 2003 & -21.200 \\
Kosoglou 2004 & -1.900 \\
Sasaki 2002 & -4.960 \\
Wagner 2005 & -5.600 \\
Ooi 2012 & -1.440 \\
Vega 2003 & -3.500 \\
& -2.700 \\
& -3.466 \\
& -4.046
\end{tabular}

Statistics for each study

Standard
error Variance $\begin{gathered}\text { Lower } \\ \text { limit }\end{gathered} \begin{gathered}\text { Upper } \\ \text { limit }\end{gathered}$

$\begin{array}{llll}1.756 & 3.083 & -6.241 & 0.641\end{array}$

$\begin{array}{llll}1.564 & 2.445 & -13.644 & -7.516\end{array}$

$\begin{array}{llll}1.123 & 1.260 & -7.720 & -3.320\end{array}$

$\begin{array}{llll}2.069 & 4.282 & -10.384 & -2.272\end{array}$

$\begin{array}{llll}2.069 & 4.282 & -10.384 & -2.272 \\ 7.397 & 54.708 & -35.697 & -6.703\end{array}$

\begin{tabular}{rrrr}
2.866 & 8.216 & -7.518 & 3.718 \\
\hline
\end{tabular}

$\begin{array}{llll}5.467 & 29.891 & -15.676 & 5.756\end{array}$

$\begin{array}{llll}2.206 & 4.866 & -9.923 & -1.277\end{array}$

$\begin{array}{llll}2.114 & 4.469 & -5.583 & 2.703\end{array}$

$\begin{array}{llll}1.762 & 3.103 & -6.952 & -0.048\end{array}$

$\begin{array}{llll}1.290 & 1.665 & -5.229 & -0.171\end{array}$

$\begin{array}{llll}1.043 & 1.088 & -5.511 & -1.422\end{array}$

$\begin{array}{llll}0.931 & 0.868 & -5.872 & -2.221\end{array}$

$\begin{array}{rr} & \\ \text { z-Value } & \text { p-Value } \\ -1.595 & 0.111 \\ -6.767 & 0.000 \\ -4.917 & 0.000 \\ -3.058 & 0.002 \\ -2.866 & 0.004 \\ -0.663 & 0.507 \\ -0.907 & 0.364 \\ -2.539 & 0.011 \\ -0.681 & 0.496 \\ -1.987 & 0.047 \\ -2.092 & 0.036 \\ -3.323 & 0.001 \\ -4.344 & 0.000\end{array}$

Difference in means and $95 \% \mathrm{Cl}$

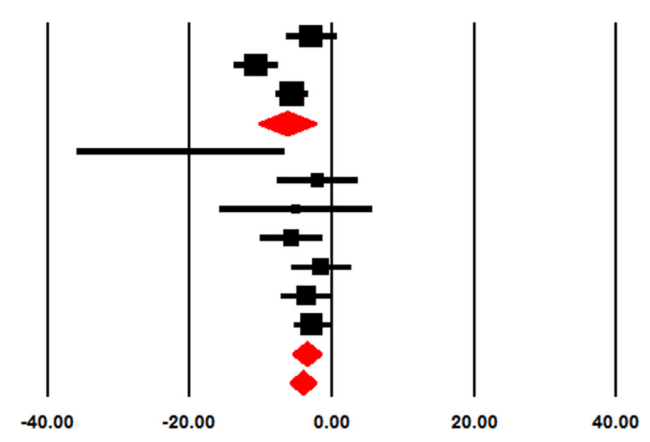

Favours Fenofibrate Favours Placebo

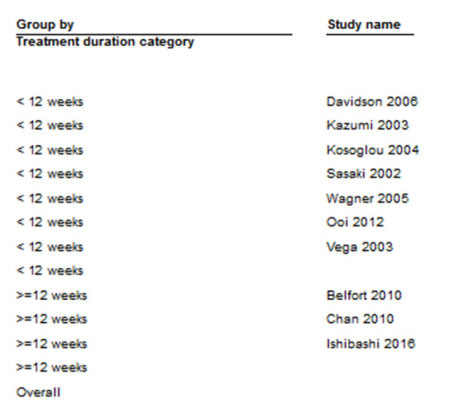

$\begin{array}{cc}\begin{array}{c}\text { Difference } \\ \text { in means }\end{array} & \begin{array}{c}\text { Standard } \\ \text { error }\end{array} \\ -10.580 & 1.584 \\ -1.900 & 2.868 \\ -4.980 & 5.467 \\ -5.600 & 2.206 \\ -1.440 & 2.114 \\ -3.500 & 1.762 \\ -2.700 & 1.290 \\ -4.481 & 1.449 \\ -21.200 & 7.397 \\ -2.800 & 1.756 \\ -5.520 & 1.123 \\ -5.658 & 2.294 \\ -4.817 & 1.225\end{array}$

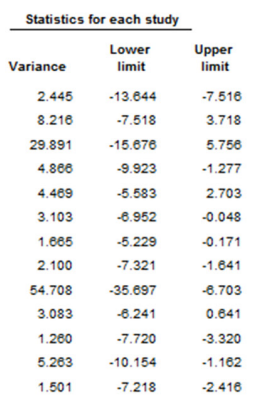

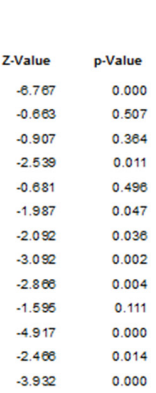

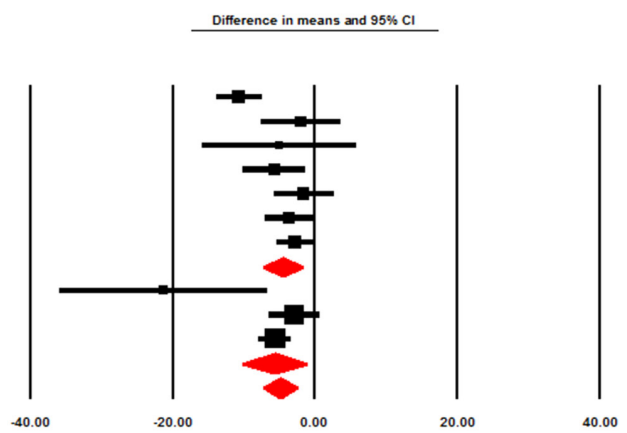

Favours Fenofibrate Favours Placebo

Figure 3 Forest plot displaying weighted mean difference and $95 \%$ Cls for the effects of different doses (<200 mg/day vs $\geq 200 \mathrm{mg} /$ day) and durations ( $<12$ weeks vs $\geq 12$ weeks) of treatment with fenofibrate on circulating apolipoprotein C-III concentrations. Analyses were performed using a random-effects model.

significant difference between the subgroups treated with different fenofibrate doses $(p=0.217)$ (figure 3).

\section{Meta-regression}

Random-effects meta-regression was performed to assess the impact of potential confounders on the effects of fenofibrate on plasma apo C-III levels. The results suggested a significant association between the apo C-III-lowering effect of fenofibrate with baseline apo C-III (slope -0.40 ; $95 \% \mathrm{CI}-0.58$ to $-0.22 ; \mathrm{p}<0.001)$ and baseline triglyceride (slope $-0.02 ; 95 \%$ CI -0.03 to $-0.01 ; \mathrm{p}=0.001$ ) concentrations. However, no significant association between the apo C-III-lowering and triglyceride-lowering effects of fenofibrate was found (slope $0.11 ; 95 \%$ CI -0.05 to $0.27 ; \mathrm{p}=0.185)$ nor were there any association with baseline LDL-C (slope $-0.02 ; 95 \%$ CI -0.12 to $0.08 ; \mathrm{p}=0.677$ ), HDL-cholesterol (HDL-C) (slope 0.35 ; $95 \%$ CI -0.29 to $0.98 ; \mathrm{p}=0.284$ ) and BMI (slope $-0.75 ; 95 \%$ CI -2.08 to $0.58 ; \mathrm{p}=0.269)$.

\section{Publication bias}

Visual inspection of Begg's funnel plots revealed a slight asymmetry in the meta-analysis of fenofibrate's effect on plasma apo C-III levels that was imputed by one potentially missing study at the left side of the plot using 'trim and fill' method that yielded an adjusted effect size of
$-5.18(-7.28$ to -3.09$)$ (figure 4). Begg's rank correlation $(p=0.592)$ and Egger's regression $(p=0.718)$ tests did not suggest the presence of publication bias. The results of 'fail-safe N' test suggested that 153 missing studies would be required to make the observed significant result non-significant.

\section{DISCUSSION}

In this meta-analysis of randomised placebo-controlled clinical trials, fenofibrate therapy was related to a significant reduction of apo C-III levels. Subanalyses revealed that this effect was observed even in those trials whose duration was less than 12 weeks and for doses of fenofibrate both higher and lower than $200 \mathrm{mg}$ /day. Moreover, the apo C-III-lowering effect of fenofibrate was found to be directly proportional to baseline apo C-III and triglycerides levels, suggesting that greater effects on plasma apo C-III levels are anticipated in populations with hyperapolipoproteinaemia C-III hypertriglyceridaemia. However, there were no associations between apo C-III-lowering effect of fenofibrate with baseline BMI, LDL-C and HDL-C, and the changes in plasma triglycerides levels. The latter finding on the lack of any association between changes in plasma apo C-III and 


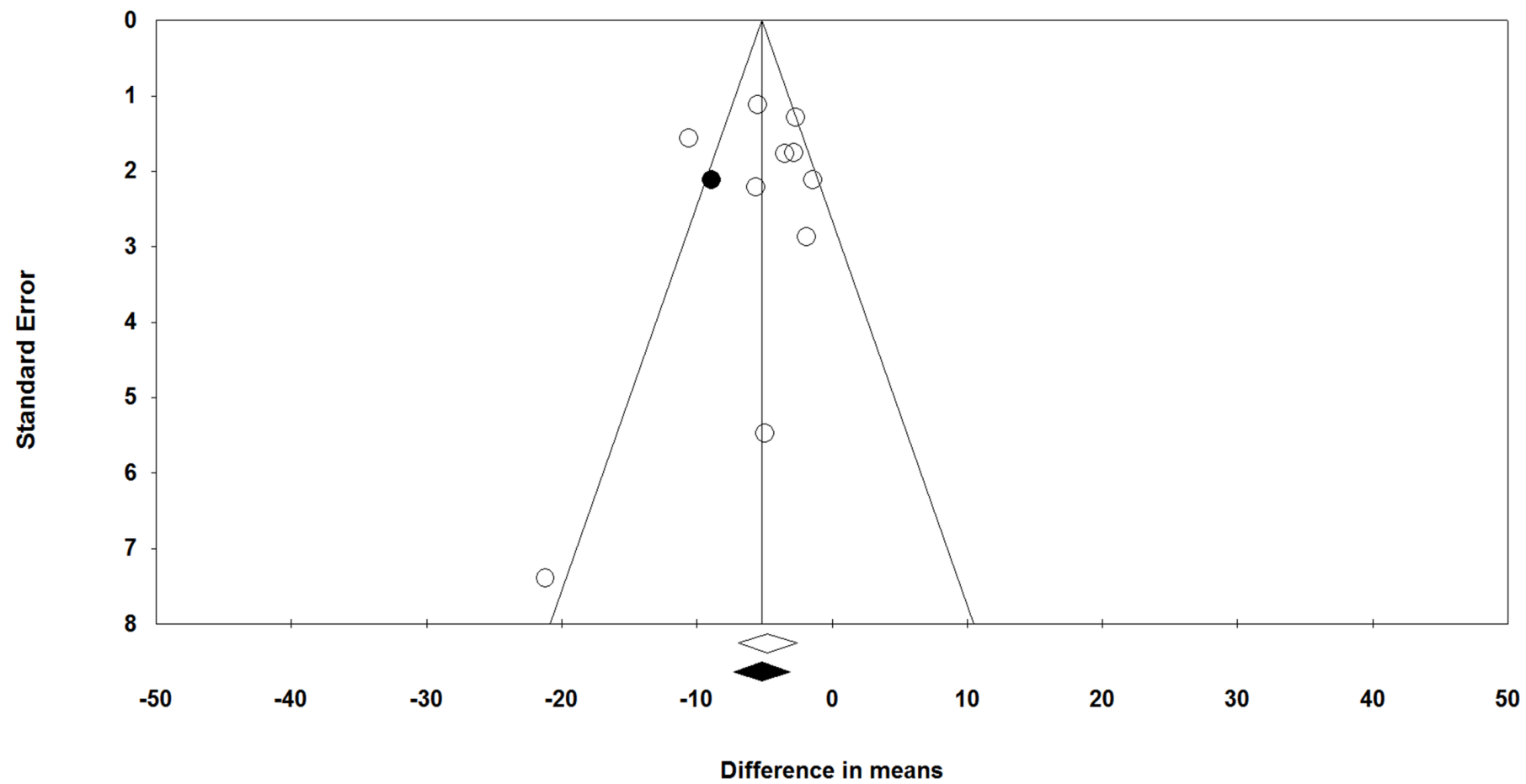

Figure 4 Random-effects funnel plot detailing publication bias in the studies reporting the impact of fenofibrate on plasma apo C-III concentrations.

triglycerides levels could be attributed to the fact that not all VLDL particles (as the main carriers of apo C-III in plasma) contain apo C-III. It has been estimated that apo C-III is present in about $50 \%$ of plasma VLDL particles. This might justify the lack of apo C-III reduction proportional to triglycerides reduction following fenofibrate therapy. ${ }^{42}$

The reduction of apo C-III levels by fenofibrate therapy may contribute to a reduced risk of CAD achieved with fibrates therapy ${ }^{43-45}$; however, the mechanism(s) by which apo C-III increases CAD risk remain(s) unclear. ${ }^{7}$ Loss of function mutations of the $A P O C 3$ gene are associated with reduced triglyceride and VLDL levels, ${ }^{46}$ whereas genetic variations have linked $A P O C 3$ to $\mathrm{CAD}$ risk. ${ }^{47}$ Epidemiological studies have found an association between increased apo C-III and $\mathrm{CAD}$ that correlated with elevated triglyceride levels. ${ }^{78-50}$ It has also been shown that accumulation of apo C-III and triglycerides in the necrotic core predisposes to plaque vulnerability in patients with stable $\mathrm{CAD}^{51}$; hence, the significant lowering effect of fenofibrate on both of these parameters might justify its potential efficacy in preventing plaque rupture and acute $\mathrm{CV}$ events, as shown for statin therapy. ${ }^{52}$ In addition, there is evidence in vivo showing the stabilising and regressing effects of fenofibrate ${ }^{5354}$ on the atherosclerotic plaque. It has been shown that elevated triglycerides and low HDL-C are not only associated with macrovascular atherosclerotic changes such as $\mathrm{CAD}$, but they are also risk factors for microvascular disease in type 2 diabetes mellitus. ${ }^{43}$ Indeed, in addition to the association with elevated triglyceride-rich particles such as VLDL number and size, increased apo C-III levels were also related to increased IDL particles numbers and a shift to more atherogenic small dense LDL particles. ${ }^{720}$ Small dense LDL exerts atherogenic properties and has been linked to increased cardiovascular risk as well as to the presence of metabolic disorders including obesity, metabolic syndrome and type 2 diabetes. ${ }^{55-57}$ Some speculate that it is quite unlikely that elevated triglycerides per se might be associated with an increased risk of CAD. However, triglyceride-rich particles such as VLDL and IDL could accumulate in the intima, and can be further catabolised and ingested by macrophages to form foam cells, resulting in progression of the atherosclerotic lesion. ${ }^{58}$ Apo C-III may therefore be seen as a therapeutic target to reduce $\mathrm{CAD}$, and antisense RNA inhibition has shown dramatic decreases in triglyceride levels. ${ }^{45}$

In the EPIC study, mediation analysis showed that a large part of the increased CAD risk associated with apo C-III was attributable to the triglyceride-rich remnant particle levels. ${ }^{7}$ This fits well with the mechanism proposed above. It has been also proven that fenofibrate decreases triglyceride-rich remnant particles. ${ }^{59} 60$ However, it was also shown that apo C-III was associated with an increased $\mathrm{C}$ reactive protein, a marker of inflammation that may represent an independent predictor of increased CAD risk. ${ }^{61}$ This finding may also reflect the LPL-independent mechanism of increased CAD risk by apo C-III.

The present meta-analysis suggested that the effect of apo C-III lowering was relatively rapid as it was observed within 12 weeks, thus indicating the early potential benefit of fibrate therapy. However, no data exist that relate triglycerides reduction and remnant particles changes induced by apo C-III. Of note, the reduction of apo C-III levels was also observed with fenofibrate doses $<200 \mathrm{mg} /$ day, but it is unclear whether a reduction in apo C-III may 
occur even if in the absence of a therapeutic decrease in triglyceride levels.

The main limitation of the present meta-analysis is that several trials were characterised by a small population size and a limited number of individuals. However, the pooled population analysed was sufficiently robust due to other studies that provided a large population size. In addition, included studies did not define elevated plasma apo C-III levels among the inclusion criteria and hence future trials specifically defined in populations with hyperapolipoproteinaemia C-III might be interesting. Finally, included the trials did not provide gender-stratified results for the impact of fenofibrate on plasma apo C-III levels; therefore, the presence of any gender effect on the apo C-III-lowering activity of fenofibrate needs to be evaluated in further studies.

\section{Conclusion}

The results of the present meta-analysis showed that fenofibrate treatment significantly decreases apo C-III levels, even with short-term treatment and doses $<200 \mathrm{mg}$ daily.

\section{Author affiliations}

${ }^{1}$ Biotechnology Research Center, Pharmaceutical Technology Institute, Mashhad University of Medical Sciences, Mashhad, Iran

${ }^{2}$ Neurogenic Inflammation Research Center, Mashhad University of Medical Sciences, Mashhad, Iran

${ }^{3}$ School of Pharmacy, Mashhad University of Medical Sciences, Mashhad, Iran ${ }^{4}$ Biomedical Research Unit, Mexican Social Security Institute, Durango, Mexico ${ }^{5}$ Second Propedeutic Department of Internal Medicine, Medical School, Aristotle University of Thessaloniki, Hippocration Hospital, Thessaloniki, Greece

${ }^{6}$ Department of Internal medicine, University Hospital Center Zagreb, University of Zagreb, Zagreb, Croatia

${ }^{7}$ Department of Hypertension, WAM University Hospital in Lodz, Medical University of Lodz, Lodz, Poland

${ }^{8}$ Polish Mother's Memorial Hospital Research Institute (PMMHRI), Lodz, Poland ${ }^{9}$ Unit of Internal Medicine, Angiology and Arteriosclerosis Diseases, Department of Medicine, University of Perugia, Perugia, Italy

${ }^{10}$ Weill Cornell Medicine Qatar, Doha, Qatar

Contributors AS and LES-M contributed to the literature search, article screening, data acquisition and abstraction. AS contributed to the statistical analysis. SLA, AS and LES-M contributed to interpretation of the results and drafting of the manuscript. NK, ŽR, MB and MP contributed to critical revision of the manuscript. All authors approved the final version of the manuscript for submission.

Funding The authors have not declared a specific grant for this research from any funding agency in the public, commercial or not-for-profit sectors.

Competing interests NK has given talks, attended conferences and participated in trials sponsored by Amgen, Angelini, Astra Zeneca, Boehringer Ingelheim, Elpen, MSD, Novartis, NovoNordisk, Sanofi and WinMedica. MB has served on speaker's bureau and as an advisory board member for Amgen, Sanofi-Aventis and Lilly.

Patient consent Not required.

Provenance and peer review Not commissioned; externally peer reviewed. Data sharing statement All data are shown in the manuscript.

Open access This is an open access article distributed in accordance with the Creative Commons Attribution Non Commercial (CC BY-NC 4.0) license, which permits others to distribute, remix, adapt, build upon this work non-commercially, and license their derivative works on different terms, provided the original work is properly cited, appropriate credit is given, any changes made indicated, and the use is non-commercial. See: http:// creativecommons.org/licenses/by-nc/4.0/.

\section{REFERENCES}

1. Sarwar N, Danesh J, Eiriksdottir G, et al. Triglycerides and the risk of coronary heart disease: 10,158 incident cases among 262,525 participants in 29 Western prospective studies. Circulation 2007;115:450-8.

2. Catapano AL, Graham I, De Backer G, et al. 2016 ESC/EAS Guidelines for the Management of Dyslipidaemias. Eur Heart $J$ 2016;37:2999-3058.

3. Reiner Ž. Hypertriglyceridaemia and risk of coronary artery disease. Nat Rev Cardiol 2017;14:401-11.

4. Gaudet D, Brisson D, Tremblay K, et al. Targeting APOC3 in the familial chylomicronemia syndrome. N Engl J Med 2014;371:2200-6.

5. Gaudet D, Alexander VJ, Baker BF, et al. Antisense Inhibition of Apolipoprotein C-III in Patients with Hypertriglyceridemia. N Engl J Med 2015;373:438-47.

6. Mendivil CO, Zheng C, Furtado J, et al. Metabolism of verylow-density lipoprotein and low-density lipoprotein containing apolipoprotein C-III and not other small apolipoproteins. Arterioscler Thromb Vasc Biol 2010;30:239-45.

7. van Capelleveen JC, Bernelot Moens SJ, Yang X, et al. Apolipoprotein C-III Levels and Incident Coronary Artery Disease Risk: The EPIC-Norfolk Prospective Population Study. Arterioscler Thromb Vasc Biol 2017;37:1206-12.

8. Zheng C. Updates on apolipoprotein CIII: fulfilling promise as a therapeutic target for hypertriglyceridemia and cardiovascular disease. Curr Opin Lipidol 2014;25:35-9.

9. Shah A, Rader DJ, Millar JS. The effect of PPAR-alpha agonism on apolipoprotein metabolism in humans. Atherosclerosis 2010;210:35-40.

10. Fruchart JC, Sacks FM, Hermans MP, et al. The Residual Risk Reduction Initiative: a call to action to reduce residual vascular risk in dyslipidaemic patient. Diab Vasc Dis Res 2008;5:319-35.

11. Chapman MJ, Ginsberg HN, Amarenco P, et al. Triglyceride-rich lipoproteins and high-density lipoprotein cholesterol in patients at high risk of cardiovascular disease: evidence and guidance for management. Eur Heart J 2011;32:1345-61.

12. Derosa G, Maffioli P, Sahebkar A. Plasma uric acid concentrations are reduced by fenofibrate: a systematic review and metaanalysis of randomized placebo-controlled trials. Pharmacol Res 2015;102:63-70.

13. Sahebkar A, Giua R, Pedone C, et al. Fibrate therapy and flow-mediated dilation: a systematic review and meta-analysis of randomized placebo-controlled trials. Pharmacol Res 2016;111:163-79.

14. Sahebkar A, Hernández-Aguilera A, Abelló D, et al. Systematic review and meta-analysis deciphering the impact of fibrates on paraoxonase-1 status. Metabolism 2016;65:609-22.

15. Sahebkar A, Serban MC, Mikhailidis DP, et al. Head-to-head comparison of statins versus fibrates in reducing plasma fibrinogen concentrations: A systematic review and meta-analysis. Pharmacol Res 2016;103:236-52.

16. Sahebkar A, Simental-Mendía LE, Watts GF, et al. Impact of fibrate therapy on plasma plasminogen activator inhibitor-1: a systematic review and meta-analysis of randomized controlled trials. Atherosclerosis 2015;240:284-96.

17. Sahebkar A, Simental-Mendía LE, Watts GF, et al. Comparison of the effects of fibrates versus statins on plasma lipoprotein(a) concentrations: a systematic review and meta-analysis of head-tohead randomized controlled trials. BMC Med 2017;15:22.

18. Sahebkar A, Watts GF. Fibrate therapy and circulating adiponectin concentrations: a systematic review and metaanalysis of randomized placebo-controlled trials. Atherosclerosis 2013;230:110-20.

19. Farnier M. Update on the clinical utility of fenofibrate in mixed dyslipidemias: mechanisms of action and rational prescribing. Vasc Health Risk Manag 2008;4:991-1000.

20. Katsiki N, Nikolic D, Montalto G, et al. The role of fibrate treatment in dyslipidemia: an overview. Curr Pharm Des 2013;19:3124-31.

21. Vrablík M, Češka R. Treatment of hypertriglyceridemia: a review of current options. Physiol Res 2015;64:S331-40.

22. Mansour M. The roles of peroxisome proliferator-activated receptors in the metabolic syndrome. Prog Mol Biol Trans/ Sci 2014;121:217-66.

23. Kersten S. Peroxisome proliferator activated receptors and lipoprotein metabolism. PPAR Res 2008;2008:1-11.

24. Serban C, Sahebkar A, Ursoniu S, et al. A systematic review and meta-analysis of the effect of statins on plasma asymmetric dimethylarginine concentrations. Sci Rep 2015;5:9902.

25. Moher D, Liberati A, Tetzlaff J, et al. Preferred reporting items for systematic reviews and meta-analyses: the PRISMA statement. BMJ 2009;339:b2535. 
26. Higgins JPT GS, ed. Cochrane handbook for systematic reviews of interventions. London, 2009.

27. Sahebkar A. Does PPAR 2 gene Pro12Ala polymorphism affect nonalcoholic fatty liver disease risk? Evidence from a meta-analysis. DNA Cell Biol 2013;32:188-98.

28. Sahebkar A, Cicero AFG, Simental-Mendía LE, et al. Curcumin downregulates human tumor necrosis factor- $\alpha$ levels: A systematic review and meta-analysis ofrandomized controlled trials. Pharmacol Res 2016;107:234-42.

29. Duval S, Tweedie R. Trim and fill: A simple funnel-plot-based method of testing and adjusting for publication bias in meta-analysis. Biometrics 2000;56:455-63.

30. Belfort R, Berria R, Cornell J, et al. Fenofibrate reduces systemic inflammation markers independent of its effects on lipid and glucose metabolism in patients with the metabolic syndrome. J Clin Endocrinol Metab 2010;95:829-36.

31. Chan DC, Hamilton SJ, Rye KA, et al. Fenofibrate concomitantly decreases serum proprotein convertase subtilisin/kexin type 9 and very-low-density lipoprotein particle concentrations in statin-treated type 2 diabetic patients. Diabetes Obes Metab 2010;12:752-6.

32. Davidson $\mathrm{MH}$, Bays HE, Stein $\mathrm{E}$, et al. Effects of fenofibrate on atherogenic dyslipidemia in hypertriglyceridemic subjects. Clin Cardiol 2006;29:268-73.

33. Hamilton SJ, Chew GT, Davis TM, et al. Fenofibrate improves endothelial function in the brachial artery and forearm resistance arterioles of statin-treated Type 2 diabetic patients. Clin Sci 2010;118:607-15.

34. Ishibashi S, Yamashita S, Arai H, et al. Effects of K-877, a novel selective PPAR $\alpha$ modulator (SPPARM $\alpha$ ), in dyslipidaemic patients: A randomized, double blind, active- and placebo-controlled, phase 2 trial. Atherosclerosis 2016;249:36-43.

35. Kazumi T, Hirano T, Yoshino G, et al. Effects of fenofibrate on albuminuria in patients with hypertriglyceridemia and/ or hyperuricemia: a multicenter, randomized, double-blind, placebo-controlled, crossover study. Curr Ther Res Clin Exp 2003;64:434-46.

36. Kosoglou T, Statkevich P, Fruchart JC, et al. Pharmacodynamic and pharmacokinetic interaction between fenofibrate and ezetimibe. Curr Med Res Opin 2004;20:1197-207.

37. Ooi EM, Ng TW, Watts GF, et al. Effect of fenofibrate and atorvastatin on VLDL apoE metabolism in men with the metabolic syndrome. $J$ Lipid Res 2012;53:2443-9.

38. Sasaki J, Yamamoto K, Ageta M. Effects of fenofibrate on highdensity lipoprotein particle size in patients with hyperlipidemia: a randomized, double-blind, placebo-controlled, multicenter, crossover study. Clin Ther 2002;24:1614-26.

39. Vega GL, Cater NB, Hadizadeh DR, et al. Free fatty acid metabolism during fenofibrate treatment of the metabolic syndrome. Clin Pharmacol Ther 2003;74:236-44.

40. Wagner JA, Larson PJ, Weiss S, et al. Individual and combined effects of peroxisome proliferator-activated receptor and \{gamma\} agonists, fenofibrate and rosiglitazone, on biomarkers of lipid and glucose metabolism in healthy nondiabetic volunteers. J Clin Pharmacol 2005;45:504-13.

41. Grey A, Bolland M, Gamble G, et al. The peroxisome proliferatoractivated receptor-gamma agonist rosiglitazone decreases bone formation and bone mineral density in healthy postmenopausal women: a randomized, controlled trial. J Clin Endocrinol Metab 2007;92:1305-10.

42. Sacks FM, Zheng C, Cohn JS. Complexities of plasma apolipoprotein C-III metabolism. J Lipid Res 2011:52:1067-70.

43. Keech A, Simes RJ, Barter P, et al. Effects of long-term fenofibrate therapy on cardiovascular events in 9795 people with type 2 diabetes mellitus (the FIELD study): randomised controlled trial. Lancet 2005;366:1849-61.
44. Lee M, Saver JL, Towfighi A, et al. Efficacy of fibrates for cardiovascular risk reduction in persons with atherogenic dyslipidemia: a meta-analysis. Atherosclerosis 2011;217:492-8.

45. Rubins HB, Robins SJ, Collins D, et al. Diabetes, plasma insulin, and cardiovascular disease: subgroup analysis from the Department of Veterans Affairs high-density lipoprotein intervention trial (VA-HIT). Arch Intern Med 2002:162:2597-604.

46. Pollin TI, Damcott CM, Shen $\mathrm{H}$, et al. A null mutation in human APOC3 confers a favorable plasma lipid profile and apparent cardioprotection. Science 2008;322:1702-5.

47. Crosby J, Peloso GM, Auer PL, et al. Loss-of-function mutations in APOC3, triglycerides, and coronary disease. N Engl J Med 2014:371:22-31.

48. Wyler von Ballmoos MC, Haring B, Sacks FM. The risk of cardiovascular events with increased apolipoprotein CIII: A systematic review and meta-analysis. J Clin Lipidol 2015;9:498-510.

49. Scheffer PG, Teerlink T, Dekker JM, et al. Increased plasma apolipoprotein C-III concentration independently predicts cardiovascular mortality: the Hoorn Study. Clin Chem 2008;54:1325-30.

50. Pechlaner R, Tsimikas S, Yin X, et al. Very-Low-Density LipoproteinAssociated Apolipoproteins Predict Cardiovascular Events and Are Lowered by Inhibition of APOC-III. J Am Coll Cardiol 2017;69:789-800.

51. Ohwada T, Watanabae K, Sakamoto T, et al. Apolipoprotein CIII and triglycerides in the necrotic core contribute to plaque vulnerability in patients with stable coronary disease. European Journal of Cardiology 2017;5:42-3.

52. Gili S, lannaccone M, Colombo F, et al. Effects of statins on plaque rupture assessed by optical coherence tomography in patients presenting with acute coronary syndromes: insights from the optical coherence tomography (OCT)-FORMIDABLE registry. Eur Heart $J$ Cardiovasc Imaging 2018;19:524-31.

53. Jeanpierre E, Le Tourneau T, Zawadzki C, et al. Beneficial effects of fenofibrate on plaque thrombogenicity and plaque stability in atherosclerotic rabbits. Cardiovasc Pathol 2009;18:140-7.

54. Corti R, Osende J, Hutter R, et al. Fenofibrate induces plaque regression in hypercholesterolemic atherosclerotic rabbits: in vivo demonstration by high-resolution MRI. Atherosclerosis 2007;190:106-13.

55. Oravec S, Dukat A, Gavornik P, et al. Atherogenic versus nonatherogenic lipoprotein profiles in healthy individuals. is there a need to change our approach to diagnosing dyslipidemia? Curr Med Chem 2014;21:2892-901.

56. Mikhailidis DP, Elisaf M, Rizzo M, et al. European panel on low density lipoprotein (LDL) subclasses: a statement on the pathophysiology, atherogenicity and clinical significance of LDL subclasses: executive summary. Curr Vasc Pharmacol 2011;9:531-2.

57. Katsiki N, Tentolouris N, Mikhailidis DP. Dyslipidaemia in type 2 diabetes mellitus: bad for the heart. Curr Opin Cardiol 2017;32:422-9.

58. Lindqvist $\mathrm{P}$, Ostlund-Lindqvist AM, Witztum JL, et al. The role of lipoprotein lipase in the metabolism of triglyceride-rich lipoproteins by macrophages. J Biol Chem 1983;258:9086-92.

59. Ferrari R, Aguiar C, Alegria E, et al. Current practice in identifying and treating cardiovascular risk, with a focus on residual risk associated with atherogenic dyslipidaemia. Eur Heart J Suppl 2016;18:C2-12.

60. Aguiar C, Alegria E, Bonadonna RC, et al. A review of the evidence on reducing macrovascular risk in patients with atherogenic dyslipidaemia: A report from an expert consensus meeting on the role of fenofibrate-statin combination therapy. Atheroscler Suppl 2015;19:1-12.

61. Ridker PM, Danielson E, Fonseca FA, et al. Rosuvastatin to prevent vascular events in men and women with elevated C-reactive protein N Engl J Med 2008;359:2195-207. 